« Monetary and fiscal policy interactions with central bank transparency and public investment »

\section{$\underline{\text { Auteurs }}$}

Meixing Dai, Moïse Sidiropoulos

Document de Travail n²010 - 21

Septembre 2010

Faculté des sciences économiques et de gestion Pôle européen de gestion et d'économie (PEGE) 61 avenue de la Forêt Noire F-67085 Strasbourg Cedex

Secétariat du BETA Géraldine Manderscheidt Tél. : (33) 0368852069 Fax : (33) 0368852070 g.manderscheidt@unistra.fr http://cournot2.u-strasbg.fr/beta 


\title{
Monetary and fiscal policy interactions with central bank
}

\section{transparency and public investment}

\author{
Meixing Dai ${ }^{a}$ and Moïse Sidiropoulos ${ }^{b}$
}

\begin{abstract}
In this paper, we study how the interactions between central bank transparency and fiscal policy affect macroeconomic performance and volatility, in a framework where productivity-enhancing public investment could improve future growth potential. We analyze the effects of central bank's opacity (lack of transparency) according to the marginal effect of public investment by considering the Stackelberg equilibrium where the government is the first mover and the central bank the follower. We show that the optimal choice of tax rate and public investment, when the public investment is highly productivity-enhancing, eliminates the effects of distortionary taxation and fully counterbalance both the direct and the fiscal-disciplining effects of opacity, on the level and variability of inflation and output gap. In the case where the public investment is not sufficiently productivity-enhancing, opacity could still have some disciplining effects as in the benchmark model, which ignores the effects of public investment.
\end{abstract}

Keywords: Distortionary taxes, output distortions, productivity-enhancing public investment, central bank transparency (opacity), fiscal disciplining effect.

JEL classification numbers: E52, E58, E62, E63, H21, H30.

\footnotetext{
${ }^{\text {a }}$ BETA, University of Strasbourg, 61, avenue de la Forêt Noire - 67085 Strasbourg Cedex - France; Tel (33) 0368 8521 31; Fax (33) 03688520 71; e-mail : dai@unistra.fr.

${ }^{\mathrm{b}}$ LEAP, Department of Economics, Aristotle University of Thessaloniki, Thessaloniki, Greece 54124, E-mail: msidiro@econ.auth.gr, Phone: (30) 23109987 10; and BETA, University of Strasbourg, 61, avenue de la Forêt Noire - 67085 Strasbourg Cedex - France; Tel (33) 0368852085 ; Fax (33) 036885 20 71; e-mail: sidiro@cournot.u-strasbg.fr.
} 


\section{Introduction}

Over the past two decades, an increasing number of central banks have become more transparent about their objectives, procedures, rationales, models and data. This has stimulated an intensive ongoing research about the effects of central bank transparency. ${ }^{1}$ Most economists agree that openness and communication with the public are crucial for the effectiveness of monetary policy, because they allow the private sector to improve expectations and hence to make better-informed decisions (Blinder, 1998). Counterexamples have been provided, with addition of distortions, where information disclosure reduces the ability of central banks to strategically use their private information, and therefore, greater transparency may not lead to welfare improvement (e.g., Sorensen (1991), Faust and Svensson (2001), Jensen (2002), Grüner (2002), Morris and Shin (2002)). ${ }^{2}$ In effect, according to the second best theory, the removal of one distortion may not always lead to a more efficient allocation when other distortions are present.

Typical models on monetary policy transparency usually consider two players, the monetary authority and the private sector. Departing from this approach, several authors introduce monetary and fiscal policy interactions. ${ }^{3}$ In a framework where the government sets a distortionary tax rate, it was shown that uncertainty (or opacity) about the "political" preference parameter of the central bank, i.e. the relative weight assigned to inflation and output gap targets, could reduce average inflation as well as inflation and output variability (Hughes Hallett and Viegi (2003), Ciccarone et al. (2007), Hefeker and Zimmer (2010)). Higher distortionary taxes

\footnotetext{
${ }^{1}$ Pioneered by Cukierman and Metzler (1986), transparency issue has been examined both theoretically and empirically by Nolan and Schaling (1998), Faust and Svensson (2001), Chortareas et al. (2002), Eijffinger and Geraats (2006), Demertzis and Hughes Hallet (2007), among others. See Geraats (2002) and Eijffinger and van der Cruijsen (2010) for a survey of the literature.

${ }^{2}$ See Dincer and Eichengreen (2007) for a short survey about these models including distortions.

${ }^{3}$ Some researchers study the relationship between central bank transparency and the institutional design (Walsh, 2003; Hughes Hallett and Weymark, 2005; Hughes Hallett and Libich, 2006, 2009; Geraats, 2007).
} 
necessary for financing higher public expenditures will induce lower output gap and higher unemployment. Thus, central bank increases the inflation rate and workers claim higher nominal wages. In terms of macroeconomic volatility, less central bank political transparency has a disciplining effect on the fiscal authority, which could dominate the direct effect of opacity when the government cares less about the public expenditures, and the central bank is quite populist whilst the initial degree of central bank opacity is sufficiently high. ${ }^{4}$

However, the aforementioned studies do not distinguish the different components of public expenditures by separating public consumption (e.g. public sector wages and current public spending on goods) from public investment (e.g., infrastructure, health and education). A substantial theoretical and empirical research has been directed towards identifying the components of public expenditure that have significant effects on economic growth (Barro (1990)). The introduction of both public capital (infrastructures) and public services (education) as inputs in the production of final goods, theoretical models suggested that public investment generates higher growth in the long run through raising private sector productivity (e.g. Futagami et al. (1993), Cashin (1995), Glomm and Ravikumar (1997), Ghosh and Roy (2004), Hassler et al. (2007), Klein et al. (2008), Azzimonti et al. (2009)). In addition, empirical studies confirm the positive impact of public investment on productivity and output (e.g. Aschauer (1989), Morrison and Schwartz (1996), Pereira (2000), and Mittnik and Neuman (2001)).

Usually, the frameworks used in theoretical studies on public investment ignore the effects due to monetary and fiscal interactions. Cavalcanti Ferreira (1999) examines the interaction between public investment and inflation tax and has found that the distortionary effect of

\footnotetext{
${ }^{4}$ The term "political transparency" used here corresponds to the information disclosure about the weights assigned by the central bank to the output gap and inflation stabilisation. Five motives for central bank transparency (i.e. political transparency, economic transparency, procedural transparency, policy transparency and operational transparency) are defined in Geraats (2002).
} 
inflation tax is compensated by the productive effect of public expenditures. Ismihan and Ozkan (2004) consider the relationship between central bank independence and productivity-enhancing public investment, and argue that although central bank independence delivers lower inflation in the short term, it may reduce the scope for productivity-enhancing public investment and so harm future growth potential. Ismihan and Ozkan (2007) extend the previous model by taking into account the issues of public debt, and have found that, under alternative fiscal rules (balancedbudget rule, capital borrowing rule), the contribution of public investment to future output plays a key role in determining its effects on macroeconomic performance.

The distinction between public consumption and public investment could allow us to introduce in the literature of central bank transparency the effects of public investment on the aggregate supply. These effects could correct the distortionary effects of taxation and therefore interact with central bank transparency. For this purpose, we re-examine in this paper the interaction between central bank political transparency and fiscal policies in a two-period model, similar to Ismihan and Ozkan (2004), where the public investment is productivity-enhancing and could compensate, partially or totally, the distortions generated by the taxes on revenue. The aim of the paper is to investigate to what extent the disciplining effect of opacity could be generalized to a framework where the government has more than one policy instrument.

The paper is organized as follows. The next section presents the model. Section 3 presents the benchmark equilibrium where there is no productivity-enhancing public investment. Section 4 examines how the inclusion of public investment affects the effects of opacity according to the marginal effect of public investment on the aggregate supply. The last section summarizes our findings. 


\section{The model}

The two-period model of discretionary policy making is similar to the one presented by Ismihan and Ozkan (2004). To model the effects of distortionary taxes and public investment on the supply, we consider a representative competitive firm, which chooses labor to maximize profits by taking price (or inflation rate $\pi_{t}$ ), wages (hence expected inflation $\pi_{t}^{e}$ ), and tax rate $\left(\tau_{t}\right)$ on the total revenue of the firm in period $t$ as given, subject to a production technology with productivity enhanced by public investment in the previous period $\left(g_{t-1}^{i}\right)$. The normalized output-supply function is:

$$
x_{t}=\pi_{t}-\pi_{t}^{e}-\tau_{t}+\psi g_{t-1}^{i}, \quad t=1,2 ;
$$

where $x_{t}$ (in log terms) represents the normalized output (or output gap). Equation (1) captures the effects of supply-side fiscal policies on the aggregate supply of output, with the effect of distortionary taxes being clearly distinguished from that of public investment. ${ }^{5}$

The public expenditures are composed by public sector consumption $\left(g_{t}^{c}>0\right)$ and investment $\left(g_{t}^{i} \geq 0\right)$, both expressed as percentages of the output. The public investment consists of productivity-enhancing expenditures on infrastructure, health, education etc. However, as its favorable consequences indirectly affect the consumers' utility, this type of expenditure is not taken into account in the policy maker's utility function. On the contrary, public consumption made up of public sector wages, current public spending on goods and other government spending is assumed to yield immediate utility to the government. The fiscal authority's loss function is

\footnotetext{
${ }^{5}$ The variable $\tau$ allows covering a whole range of structural reforms. In effect, $\tau$ could also represent non-wage costs associated with social security (or job protection legislation), the pressures caused by tax or wage competition on a regional basis or the more general effects of supply-side deregulation (Demertzis et al., 2004).
} 


$$
L_{0}^{G}=\frac{1}{2} \mathrm{E}_{0} \sum_{t=1}^{2} \beta_{G}^{t-1}\left[\delta_{1} \pi_{t}^{2}+x_{t}^{2}+\delta_{2}\left(g_{t}^{c}-\bar{g}_{t}^{c}\right)^{2}\right]
$$

where $\mathrm{E}_{0}$ is an operator of mathematical expectations, $\beta_{G}$ the government's discount factor, $\delta_{1}$ and $\delta_{2}$ the weights assigned to the stabilization of inflation and public consumption respectively, while the output-gap stabilization is assigned a weight equal to unity.

The government's objectives are the stabilization of the inflation rate and the output gap around zero, and of the public consumption around its target $\bar{g}_{t}^{c}$. The government minimizes the above two-period loss function subject to the following budget constraint:

$$
g_{t}^{i}+g_{t}^{c}=\tau_{t}, \quad \text { with } \quad t=1,2 .
$$

Equation (3) is a simple form of the budget constraint since public debt and seigniorage revenue are not taken into account. Even though $g_{t}^{i}$ enhances the productivity in the future, it is implemented and financed in the current period.

The government delegates the conduct of the monetary policy to the central bank while it retains control of its fiscal instruments. The central bank sets its policy in order to minimize the loss function

$$
L_{0}^{C B}=\frac{1}{2} \mathrm{E}_{0} \sum_{t=1}^{2} \beta_{C B}^{t-1}\left[(\mu-\varepsilon) \pi_{t}^{2}+(1+\varepsilon) x_{t}^{2}\right], \quad \mu>0,
$$

where $\beta_{C B}$ is the central bank's discount factor. The parameter $\mu$ is the expected relative weight that the central bank assigns to the inflation target and it could be equal or different from $\delta_{1}$. It is therefore an indicator of central bank conservatism (larger $\mu$ values) versus liberalism or populism. According to the literature, we assume that the central bank can fully neutralize the effects of policy shocks (including public spending) or exogenous demand shocks affecting the goods market through appropriate setting of its policy instrument $\pi$. 
The weights assigned by the central bank to the inflation and output-gap targets are more or less predictable by the government and private sector, meaning that $\varepsilon$ is a stochastic variable. The fact that $\varepsilon$ is associated to both inflation and output objectives is adopted for avoiding the arbitrary effects of central bank preference uncertainty on average monetary policy (Beetsma and Jensen, 2003). The distribution of $\varepsilon$ is characterized by $\mathrm{E}(\varepsilon)=0, \operatorname{var}(\varepsilon)=\mathrm{E}\left(\varepsilon^{2}\right)=\sigma_{\varepsilon}^{2}$ and $\varepsilon \in[-1, \mu]$. Variance $\sigma_{\varepsilon}^{2}$ represents the degree of opacity about central bank preferences. When $\sigma_{\varepsilon}^{2}=0$, the central bank is completely predictable and hence, completely transparent. As the random variable $\varepsilon$ is taking values in a compact set and has an expectation equal to zero, Ciccarone et al., (2007) have proved that $\sigma_{\varepsilon}^{2}$ has an upper bound so that $\sigma_{\varepsilon}^{2} \in[0, \mu]$.

The timing of the game is the following. First, the private sector forms inflation expectations, then, the government sets the tax rate and public investment, and finally the central bank chooses the inflation rate. The private sector composed of atomistic agents plays a Nash game against the central bank. The government, as Stackelberg leader, plays a Stackelberg game against the central bank. The game is solved by backward induction.

\section{The benchmark equilibrium without public investment}

First, we consider a benchmark case where the public investment has no supply-side effect. Therefore, it is optimal for the government to set its level at zero. This benchmark case is drawn directly from Hefeker and Zimmer (2010). It is different from Ciccarone et al. (2007) who also introduce distortions in the labor market through the wage determination by an all-encompassing monopoly union, as well as from Hughes Hallett and Viegi (2003) who consider a Nash game between the fiscal and monetary authorities, both concerned by distortionary taxes. 
Equations (1) and (3) are rewritten as:

$$
\begin{aligned}
& x_{t}=\pi_{t}-\pi_{t}^{e}-\tau_{t}, \\
& g_{t}^{c}=\tau_{t} .
\end{aligned}
$$

The central bank minimizes the loss function (4) subject to (5). Its reaction function is:

$$
\pi_{t}=\frac{(1+\varepsilon)\left(\pi_{t}^{e}+\tau_{t}\right)}{1+\mu}
$$

Equations (5)-(7) allow us to express the output gap as:

$$
x_{t}=\frac{-(\mu-\varepsilon)\left(\pi_{t}^{e}+\tau_{t}\right)}{1+\mu} .
$$

The government has only one instrument to choose between the tax rate and public consumption due to the budget constraint (6). Setting its fiscal policy, the government cannot predict (7)-(8) with precision due to imperfect disclosure of information about the central bank preferences. Substituting $g_{t}^{c}, \pi_{t}$ and $x_{t}$ given by (6)-(8), the government's constrained minimization problem is rewritten, after rearranging the terms, as an unconstrained minimization problem:

$$
\min _{\tau_{t}} L_{0}^{G}=\frac{1}{2} \mathrm{E}_{0} \sum_{t=1}^{2} \beta_{G}^{t-1}\left\{\frac{(\varepsilon-\mu)^{2}+\delta_{1}(1+\varepsilon)^{2}}{(1+\mu)^{2}}\left(\pi_{t}^{e}+\tau_{t}\right)^{2}+\delta_{2}\left(\tau_{t}-\bar{g}_{t}^{c}\right)^{2}\right\} .
$$

Using the second-order Taylor approximation to obtain $\Theta=\mathrm{E}\left[\frac{(\varepsilon-\mu)^{2}+\delta_{1}(1+\varepsilon)^{2}}{(1+\mu)^{2}}\right] \approx \frac{\mu^{2}+\delta_{1}}{(1+\mu)^{2}}+\frac{\left(1+\delta_{1}\right)}{(1+\mu)^{2}} \sigma_{\varepsilon}^{2}$, the government's loss function is rewritten as

$$
L_{0}^{G} \cong \frac{1}{2} \sum_{t=1}^{2} \beta_{G}^{t-1}\left[\Theta\left(\pi_{t}^{e}+\tau_{t}\right)^{2}+\delta_{2}\left(\tau_{t}-\bar{g}_{t}^{c}\right)^{2}\right]
$$

Proposition 1. For given expected inflation and tax rate, an increase in central bank's opacity generally induces higher social welfare loss. 
Proof. Deriving (10) with respect to $\sigma_{\varepsilon}^{2}$ yields $\frac{\partial L_{0}^{G}}{\partial \sigma_{\varepsilon}^{2}} \cong \frac{1}{2} \sum_{t=1}^{2} \beta_{G}^{t-1}\left[\frac{1+\delta_{1}}{(1+\mu)^{2}}\left(\pi_{t}^{e}+\tau_{t}\right)^{2}\right]>0$ if $\pi_{t}^{e}+\tau_{t} \neq 0$

As the government has an objective of public consumption, $\tau_{t}$ cannot be fixed in a way to completely neutralize the effects of central bank's opacity in the social loss function. If the government sets $\tau_{t}=-\pi_{t}^{e}$ to neutralize the effects of opacity on the social loss function, it will suffer from high marginal cost due to insufficient public consumption. Hence, the optimal level of the tax rate depends on the degree of opacity. From the first-order condition of the government's minimization problem we obtain:

$$
\tau_{t}=\frac{\delta_{2} \bar{g}_{t}^{c}-\Theta \pi_{t}^{e}}{\Theta+\delta_{2}}=\frac{\delta_{2}(\mu+1)^{2} \bar{g}_{t}^{c}-\left[\left(\mu^{2}+\delta_{1}\right)+\left(1+\delta_{1}\right) \sigma_{\varepsilon}^{2}\right] \pi_{t}^{e}}{\mu^{2}+\delta_{1}+\left(1+\delta_{1}\right) \sigma_{\varepsilon}^{2}+\delta_{2}(1+\mu)^{2}} .
$$

Substituting $\tau_{t}$ given by (11) into (7) and imposing rational expectations yields:

$$
\pi_{t}^{e}=\frac{\delta_{2} \bar{g}_{t}^{c}}{\delta_{2} \mu+\Theta(1+\mu)}=\frac{\delta_{2}(1+\mu) \bar{g}_{t}^{c}}{\delta_{2} \mu(1+\mu)+\mu^{2}+\delta_{1}+\left(1+\delta_{1}\right) \sigma_{\varepsilon}^{2}} .
$$

Substituting $\pi_{t}^{e}$ given by (12) into (11) and taking account of (6) lead to:

$$
\tau_{t}=g_{t}^{c}=\frac{\delta_{2} \mu \bar{g}_{t}^{c}}{\delta_{2} \mu+\Theta(1+\mu)}=\frac{\delta_{2} \mu(1+\mu) \bar{g}_{t}^{c}}{\delta_{2} \mu(1+\mu)+\mu^{2}+\delta_{1}+\left(1+\delta_{1}\right) \sigma_{\varepsilon}^{2}} .
$$

Using (12)-(13) into (7)-(8) and the budget constraint (6) yields:

$$
\begin{aligned}
& \pi_{t}=\frac{(1+\varepsilon) \delta_{2} \bar{g}_{t}^{c}}{\delta_{2} \mu+\Theta(1+\mu)}=\frac{(1+\varepsilon) \delta_{2}(1+\mu) \bar{g}_{t}^{c}}{\delta_{2} \mu(1+\mu)+\mu^{2}+\delta_{1}+\left(1+\delta_{1}\right) \sigma_{\varepsilon}^{2}}, \\
& x_{t}=\frac{(\varepsilon-\mu) \delta_{2} \bar{g}_{t}^{c}}{\delta_{2} \mu+\Theta(1+\mu)}=\frac{(\varepsilon-\mu)(1+\mu) \delta_{2} \bar{g}_{t}^{c}}{\delta_{2} \mu(1+\mu)+\mu^{2}+\delta_{1}+\left(1+\delta_{1}\right) \sigma_{\varepsilon}^{2}}, \\
& g_{t}^{c}-\bar{g}_{t}^{c}=\frac{-\Theta(1+\mu) \bar{g}_{t}^{c}}{\delta_{2} \mu+\Theta(1+\mu)}=\frac{-\left[\mu^{2}+\delta_{1}+\left(1+\delta_{1}\right) \sigma_{\varepsilon}^{2}\right] \bar{g}_{t}^{c}}{\delta_{2} \mu(1+\mu)+\mu^{2}+\delta_{1}+\left(1+\delta_{1}\right) \sigma_{\varepsilon}^{2}} .
\end{aligned}
$$


Calculating the variance of $\pi_{t}$ and $x_{t}$ results to:

$$
\operatorname{var}\left(\pi_{t}\right)=\operatorname{var}\left(x_{t}\right)=\frac{\left(\delta_{2} \bar{g}_{t}^{c}\right)^{2} \sigma_{\varepsilon}^{2}}{\left[\delta_{2} \mu+\Theta(1+\mu)\right]^{2}}=\frac{\left[\delta_{2}(1+\mu) \bar{g}_{t}^{c}\right]^{2} \sigma_{\varepsilon}^{2}}{\left[\delta_{2} \mu(1+\mu)+\mu^{2}+\delta_{1}+\left(1+\delta_{1}\right) \sigma_{\varepsilon}^{2}\right]^{2}} .
$$

From (13)-(17), we observe that the denominator increases as the degree of opacity $\sigma_{\varepsilon}^{2}$, while the numerator of (16) decreases as $\sigma_{\varepsilon}^{2}$ and the numerator of (17) is increases as $\sigma_{\varepsilon}^{2}$. It follows that $\tau_{t}, g_{t}^{c}, \pi_{t}$ and $x_{t}$ are all decreasing in $\sigma_{\varepsilon}^{2}$. On the other hand, $\operatorname{var}\left(\pi_{t}\right)$ and $\operatorname{var}\left(x_{t}\right)$ could be both increasing or decreasing in $\sigma_{\varepsilon}^{2}$, as shown by the results of Hefeker and Zimmer (2010) that we reformulate in the following proposition.

Proposition 2. An increase in central bank's opacity reduces the tax rate, inflation and output distortions but increases deviations of public consumption from its target level. It reduces the variability of inflation and output gap if the initial degree of opacity is sufficiently high and vice versa.

Proof. Deriving $\tau_{t}, \pi_{t}, x_{t}$ and $g_{t}^{c}-\bar{g}_{t}^{c}$ given by (13)-(16) with respect to $\sigma_{\varepsilon}^{2}$, leads to the first part of Proposition 2. Deriving $\operatorname{var}\left(\pi_{t}\right)$ and $\operatorname{var}\left(x_{t}\right)$ given by (17) with respect to $\sigma_{\varepsilon}^{2}$, yields:

$$
\frac{\partial \operatorname{var}\left(\pi_{t}\right)}{\partial \sigma_{\varepsilon}^{2}}=\frac{\partial \operatorname{var}\left(x_{t}\right)}{\partial \sigma_{\varepsilon}^{2}}=\frac{\left[\delta_{2} \mu(1+\mu)+\mu^{2}+\delta_{1}-\left(1+\delta_{1}\right) \sigma_{\varepsilon}^{2}\right]\left[\delta_{2}(1+\mu) \bar{g}_{t}^{c}\right]^{2}}{\left[\delta_{2} \mu(1+\mu)+\mu^{2}+\delta_{1}+\left(1+\delta_{1}\right) \sigma_{\varepsilon}^{2}\right]^{3}} .
$$

It follows that $\frac{\partial \operatorname{var}\left(\pi_{t}\right)}{\partial \sigma_{\varepsilon}^{2}}=\frac{\partial \operatorname{var}\left(x_{t}\right)}{\partial \sigma_{\varepsilon}^{2}}>0$ if $\sigma_{\varepsilon}^{2}<\frac{\delta_{2} \mu(1+\mu)+\mu^{2}+\delta_{1}}{1+\delta_{1}}$ and vice versa.

Distortions introduced by taxes used to finance public expenditures imply higher current and expected inflation rates. Brainard's (1967) conservatism principle implies that the government is incited to adopt a less aggressive fiscal policy ("disciplining effect”) because the perceived marginal costs associated with higher taxes are higher under central bank opacity. This stance of 
fiscal policy leads to lower output gap and inflation rate at the cost of larger deviation of public consumption from its target level. In terms of macroeconomic volatility, opacity triggers two opposing effects. The first corresponds to the direct effect of opacity on the variability of inflation and output gap for a given tax rate (or given level of distortions). The second refers to the disciplining effect, since uncertainty about the central bank preference leads to greater fiscal discipline, contributing to the reduction of inflation and output volatility. The disciplining effect is more likely to dominate the direct effect of opacity if the central bank is less averse to inflation (smaller $\mu$ ) and the government is less concerned with the public consumption deviations (smaller $\delta_{2}$ ).

Using the property $\sigma_{\varepsilon}^{2} \in[0, \mu]$, shown by Ciccarone et al. (2007), we extend the previous results in the following proposition.

Proposition 3. If the government assign a sufficiently high weight to the public consumption, i.e. $\delta_{2}>\frac{\left(1+\delta_{1}\right) \mu-\left(\mu^{2}+\delta_{1}\right)}{\mu(1+\mu)}$, the disciplining effect of central bank's opacity will always be dominated by the direct effect of opacity on the variability of inflation and output gap and vice versa.

Proof. We obtain $\frac{\partial \operatorname{var}\left(\pi_{t}\right)}{\partial \sigma_{\varepsilon}^{2}}=\frac{\partial \operatorname{var}\left(x_{t}\right)}{\partial \sigma_{\varepsilon}^{2}}<0, \forall \sigma_{\varepsilon}^{2}>\frac{\left(\mu^{2}+\delta_{1}\right)+\delta_{2} \mu(1+\mu)}{\left(1+\delta_{1}\right)}$. According to Ciccarone et al. (2007), there exists an upper bound on $\sigma_{\varepsilon}^{2}$ so that $\sigma_{\varepsilon}^{2} \in[0, \mu]$. Thus, the previous lower bound on $\sigma_{\varepsilon}^{2} \quad$ is $\quad$ valid only when $\quad \frac{\left(\mu^{2}+\delta_{1}\right)+\delta_{2} \mu(1+\mu)}{\left(1+\delta_{1}\right)}<\mu$. This leads to $\delta_{2}<\frac{\left(1+\delta_{1}\right) \mu-\left(\mu^{2}+\delta_{1}\right)}{\mu(1+\mu)}$. If $\delta_{2}>\frac{\left(1+\delta_{1}\right) \mu-\left(\mu^{2}+\delta_{1}\right)}{\mu(1+\mu)}$, the only possible case is that we have always $\sigma_{\varepsilon}^{2}<\frac{\left(\mu^{2}+\delta_{1}\right)+\delta_{2} \mu(1+\mu)}{\left(1+\delta_{1}\right)}$. In this case, the direct effect of opacity will always dominate the disciplining effect.

In the following, we examine the validity of the previous results in the case where the public investment is productivity-enhancing. 


\section{Effects of productivity-enhancing public investment}

Consider that the public investment is productivity-enhancing. However, according to the marginal effect of such investment, the government might be incited to implement positive, zero or even negative public investment in period 1 or/and 2. Even though negative public investments, such as privatization of infrastructure and education institutions, are possible in practice, they cannot be captured in the present model. That is because such disinvestments are considered to generate a negative effect on the productivity while the privatization suggests a transfer of property but not an inversion of effects of such investments on the productivity. Thus, we assume that negative public investments are not allowed. This implies that we must introduce two supplementary constraints for the government, i.e. $g_{1}^{i} \geq 0$ and $g_{2}^{i} \geq 0$.

Minimizing the central bank's loss function (4) subject to the economic constraint (1) yields the central bank's reaction function:

$$
\pi_{t}=\frac{(1+\varepsilon)\left(\pi_{t}^{e}+\tau_{t}-\psi g_{t-1}^{i}\right)}{1+\mu}, \quad \text { with } \quad t=1,2
$$

Using (1)-(3) and (18), we rewrite the government's loss function as:

$$
L_{0}^{G}=\frac{1}{2}\left\{\Theta\left(\pi_{1}^{e}+\tau_{1}-\psi g_{0}^{i}\right)^{2}+\delta_{2}\left(\tau_{1}-g_{1}^{i}-\bar{g}_{1}^{c}\right)^{2}+\beta_{G}\left[\Theta\left(\pi_{2}^{e}+\tau_{2}-\psi g_{1}^{i}\right)^{2}+\delta_{2}\left(\tau_{2}-g_{2}^{i}-\bar{g}_{2}^{c}\right)^{2}\right]\right\} .
$$

Proposition 4. For given $\tau_{t}, g_{t}^{c}$ and $g_{t}^{i}$, if $\pi_{t}^{e}+\tau_{t}-\psi g_{t-1}^{i} \neq 0$, an increase in central bank's opacity induces a higher social welfare loss.

Proof. Deriving the loss function given in (19) with respect to $\sigma_{\varepsilon}^{2}$ and using the definition of $\Theta$, we obtain: $\frac{\partial L_{0}^{G}}{\partial \sigma_{\varepsilon}^{2}}=\frac{\left(1+\delta_{1}\right)}{2(1+\mu)^{2}}\left[\left(\pi_{1}^{e}+\tau_{1}-\psi g_{0}^{i}\right)^{2}+\beta_{G}\left(\pi_{2}^{e}+\tau_{2}-\psi g_{1}^{i}\right)^{2}\right]>0$ if $\pi_{t}^{e}+\tau_{t}-\psi g_{t-1}^{i} \neq 0$. 
Opacity has negative effects on the social welfare. In the absence of productivity-enhancing public investment, the government has incentive to reduce the tax rate but at the risk of increasing the deviation of public consumption from its target level. In the case of productivity-enhancing public investment, when positive interior solutions exist for public investment in two periods, the effects of past public investment allow a complete compensation of the distortions introduced by the taxes. Thus, the government is enabled to set a tax rate to ensure that the objective of public consumption is realized. Since the distortions disappear, the central bank has no incentive to set an inflation rate higher than zero. In contrast, the distortions will only be partially compensated when such interior solutions do not exist. In the following we consider the case where positive interior solutions exist for public investment and two cases of corner solutions.

\subsection{The case where positive interior solutions exist for public investment}

This is the case where the public investment is sufficiently productivity-enhancing, such that public investments are set optimally by the government at a strictly positive level in two periods. The first-order conditions of the minimization problem (19) are:

$$
\begin{aligned}
& \frac{\partial L_{t}^{G}}{\partial \tau_{1}}=\Theta\left(\pi_{1}^{e}+\tau_{1}-\psi g_{0}^{i}\right)+\delta_{2}\left(\tau_{1}-g_{1}^{i}-\bar{g}_{1}^{c}\right)=0, \\
& \frac{\partial L_{t}^{G}}{\partial g_{1}^{i}}=-\delta_{2}\left(\tau_{1}-g_{1}^{i}-\bar{g}_{1}^{c}\right)-\beta_{G} \psi \Theta\left(\pi_{2}^{e}+\tau_{2}-\psi g_{1}^{i}\right)=0, \\
& \frac{\partial L_{t}^{G}}{\partial \tau_{2}}=\beta_{G} \Theta\left(\pi_{2}^{e}+\tau_{2}-\psi g_{1}^{i}\right)+\beta_{G} \delta_{2}\left(\tau_{2}-g_{2}^{i}-\bar{g}_{2}^{c}\right)=0, \\
& \frac{\partial L_{t}^{G}}{\partial g_{2}^{i}}=-\beta_{G} \delta_{2}\left(\tau_{2}-g_{2}^{i}-\bar{g}_{2}^{c}\right)=0 .
\end{aligned}
$$

Solving (20)-(23) gives the government's reaction functions: 


$$
\begin{aligned}
& \tau_{1}=-\pi_{1}^{e}+\psi g_{0}^{i}, \\
& g_{1}^{i}=-\bar{g}_{1}^{c}-\pi_{1}^{e}+\psi g_{0}^{i}, \\
& \tau_{2}=\psi^{2} g_{0}^{i}-\psi \bar{g}_{1}^{c}-\pi_{2}^{e}-\psi \pi_{1}^{e}, \\
& g_{2}^{i}=\psi^{2} g_{0}^{i}-\psi \bar{g}_{1}^{c}-\bar{g}_{2}^{c}-\pi_{2}^{e}-\psi \pi_{1}^{e} .
\end{aligned}
$$

To determine the expected inflation rates, we substitute $\tau_{1}, g_{1}^{i}$ and $\tau_{2}$ respectively, given by (24)-(26) into (18). Imposing rational expectations yields:

$$
\pi_{1}^{e}=\pi_{2}^{e}=0
$$

Using the results given by (28) into (24)-(27) leads to the equilibrium solutions

$$
\begin{aligned}
& \tau_{1}=\psi g_{0}^{i}, \\
& g_{1}^{i}=\psi g_{0}^{i}-\bar{g}_{1}^{c}, \\
& \tau_{2}=\psi^{2} g_{0}^{i}-\psi \bar{g}_{1}^{c}, \\
& g_{2}^{i}=\psi^{2} g_{0}^{i}-\psi \bar{g}_{1}^{c}-\bar{g}_{2}^{c} .
\end{aligned}
$$

From (30) and (32), we deduce the minimal value of $\psi$ for ensuring that the optimal public investment is strictly positive in two periods, as follows:

$$
\psi>\frac{\bar{g}_{1}^{c} \pm \sqrt{\bar{g}_{1}^{c 2}+4 g_{0}^{i} \bar{g}_{2}^{c}}}{2 g_{0}^{i}} .
$$

Under this condition, we have simultaneously $g_{1}^{i}>0$ and $g_{2}^{i}>0$.

Using (29)-(32) into (3), we get the public consumptions:

$$
g_{t}^{c}=\bar{g}_{t}^{c}, \quad \text { with } \quad t=1,2 .
$$


Compared to the benchmark solution (13), the solutions of tax rate and public consumption given by (29), (31) and (33), are extremely simple. They depend only on the initial public investment, the marginal effect of public investment and the targets of public consumption.

Proposition 5. If the public investment is sufficiently productivity-enhancing, i.e. $\psi>\frac{\bar{g}_{1}^{c} \pm \sqrt{\bar{g}_{1}^{c 2}+4 g_{0}^{i} \bar{g}_{2}^{c}}}{2 g_{0}^{i}}$, the government will optimally set the tax rate and public investment such as to neutralize the effects of central bank preferences and hence the effects of opacity on its decisions.

Proof. It follows straightforward from (29)-(33).

We remark that the government's decisions given by (29)-(33) are not dependent on central bank preferences. The central bank's "type" (more or less conservative) has neither effect on the tax rate and public investment nor on their variability. Thus, the degree of transparency has no impact on these decisions. The introduction of sufficiently productivity-enhancing public investment incites the government to increase the tax rate to finance higher investment in period 1, but not necessarily in period 2. In effect, the government can collect more taxes, given the higher productivity in period 2. But, as the benefits of public investment in period 2 will be attributed to the next government, the government has no incentive to increase public investment in this period. However, the government is not urged to set the public investment in period 2 at zero, since the tax rate which neutralizes the distortions could generate more tax revenue than what is optimal to spend on the public consumption. The current government is elected on a mandate which implies that it should not set a too high public consumption to avoid the deterioration of the social welfare.

We notice that the tax rate and public investment in the two periods do not depend on the preferences of fiscal authorities. In effect, when the government, whatever are the government 
preferences, sets separately the tax rate and public investment, it must ensure that the optimal choices allow concealing the effects of these two policy instruments on production and hence inflation.

Using the results given by (28)-(31) into (1) and (18), we obtain:

$$
\begin{aligned}
& \pi_{1}=\pi_{2}=0, \\
& x_{1}=x_{2}=0 .
\end{aligned}
$$

The above equilibrium solutions show that inflation and output-gap targets of the central bank are always realized.

Proposition 6. If the public investment is sufficiently productivity-enhancing, i.e. $\psi>\frac{\bar{g}_{1}^{c} \pm \sqrt{\bar{g}_{1}^{c 2}+4 g_{0}^{i} \bar{g}_{2}^{c}}}{2 g_{0}^{i}}$, the optimal choice of tax rate and public investment by the government allows the neutralization of the effects of central bank preferences and hence the effects of opacity on the level and variability of inflation and output gap.

Proof. It follows directly from the solutions given by (34)-(35).

In contrast to the existing literature on the interaction between fiscal policies and central bank transparency, the degree of political transparency in the present case is irrelevant for the economic equilibrium and macroeconomic stabilization. This is because the government, which has two free policy instruments, is able to conceal the distortionary effects of taxes collected to finance the public expenditures through the optimal choice of tax rate and public investment. Then, the central bank has no motivation to set an inflation rate higher than the target inflation, which is zero. This is rationally expected by the wage setters, thus leading to the elimination of the output distortions. 
Our findings imply that the government could generally neutralize the effects of opacity when positive interior solutions exist for tax rates and public investments. There is neither a case against, nor a case for more opacity of the central bank. Meanwhile, in contrast to the benchmark case, the central bank has no incentive to be more opaque since the disciplining effects of opacity have disappeared.

\subsection{The cases of corner solutions for public investment}

We now consider two cases of corner solutions. In the first case, the public investment is insufficiently productivity-enhancing such that the constraints $g_{1}^{i} \geq 0$ and $g_{2}^{i} \geq 0$ are both binding. In the second case, it is quite productivity-enhancing such that only the second constraint is binding.

\section{Case 1. Public investments are set to zero in two periods}

This is the case where $\psi<\frac{\bar{g}_{1}^{c}}{g_{0}^{i}}\left(\right.$ or $\left.\psi g_{0}^{i}-\bar{g}_{1}^{c}<0\right)$, i.e. the marginal effect of the past investment on the current productivity is smaller than the ratio of public consumption target in period 1 over public investment in period 0 . Because the condition $\psi g_{0}^{i}-\bar{g}_{1}^{c}<0$ implies that $g_{1}^{i}=-\bar{g}_{1}^{c}+\psi g_{0}^{i}<0$ and $g_{2}^{i}=\psi^{2} g_{0}^{i}-\psi \bar{g}_{1}^{c}-\bar{g}_{2}^{c}=\psi g_{1}^{i}-\bar{g}_{2}^{c}<0$, the interior solutions of $g_{1}^{i}$ and $g_{2}^{i}$ are both negative. Taking into account the constraints $g_{1}^{i}, g_{2}^{i} \geq 0$, the government sets $g_{1}^{i}=g_{2}^{i}=0$. This leads to $\frac{\partial L_{t}^{G}}{\partial g_{1}^{i}}>0$ and $\frac{\partial L_{t}^{G}}{\partial g_{2}^{i}}>0$, i.e. a decrease in $g_{1}^{i}$ and $g_{2}^{i}$ will improve the social welfare. Using $g_{1}^{i}=g_{2}^{i}=0$ into the first-order conditions (20) and (22), we obtain: 


$$
\begin{aligned}
& \tau_{1}=\frac{\Theta\left(\psi g_{0}^{i}-\pi_{1}^{e}\right)+\delta_{2} \bar{g}_{1}^{c}}{\delta_{2}+\Theta}, \\
& \tau_{2}=\frac{\delta_{2} \bar{g}_{2}^{c}-\Theta \pi_{2}^{e}}{\Theta+\delta_{2}} .
\end{aligned}
$$

Using (36)-(37) in (18) and taking mathematical expectations of the resulting equations yield:

$$
\begin{aligned}
& \pi_{1}^{e}=\frac{\delta_{2}\left(\bar{g}_{1}^{c}-\psi g_{0}^{i}\right)}{\mu \delta_{2}+\Theta(1+\mu)}>0, \\
& \pi_{2}^{e}=\frac{\delta_{2} \bar{g}_{2}^{c}}{\mu \delta_{2}+\Theta(1+\mu)}>0 .
\end{aligned}
$$

Using (38)-(39) into (36)-(37) and taking account of (3) and the definition of $\Theta$, results to:

$$
\begin{aligned}
& \tau_{1}=g_{1}^{c}=\frac{\psi(1+\mu) \Theta g_{0}^{i}+\mu \delta_{2} \bar{g}_{1}^{c}}{\mu \delta_{2}+\Theta(1+\mu)}=\frac{\psi(1+\mu)\left[\mu^{2}+\delta_{1}+\left(1+\delta_{1}\right) \sigma_{\varepsilon}^{2}\right] g_{0}^{i}+\mu \delta_{2}(1+\mu) \bar{g}_{1}^{c}}{\mu \delta_{2}(1+\mu)+\left(\mu^{2}+\delta_{1}\right)+\left(1+\delta_{1}\right) \sigma_{\varepsilon}^{2}} \\
& \tau_{2}=g_{2}^{c}=\frac{\mu \delta_{2} \bar{g}_{2}^{c}}{\mu \delta_{2}+\Theta(1+\mu)}=\frac{\mu \delta_{2}(1+\mu) \bar{g}_{2}^{c}}{\mu \delta_{2}(1+\mu)+\mu^{2}+\delta_{1}+\left(1+\delta_{1}\right) \sigma_{\varepsilon}^{2}}
\end{aligned}
$$

Using (1), (3), (18), (38)-(41), $g_{1}^{i}=g_{2}^{i}=0$, and the definition of $\Theta$, we obtain:

$$
\begin{aligned}
& \pi_{1}=\frac{(1+\varepsilon) \delta_{2}\left(\bar{g}_{1}^{c}-\psi g_{0}^{i}\right)}{\mu \delta_{2}+\Theta(1+\mu)}=\frac{(1+\varepsilon) \delta_{2}(1+\mu)\left(\bar{g}_{1}^{c}-\psi g_{0}^{i}\right)}{\mu \delta_{2}(1+\mu)+\mu^{2}+\delta_{1}+\left(1+\delta_{1}\right) \sigma_{\varepsilon}^{2}}, \\
& x_{1}=\frac{(\varepsilon-\mu) \delta_{2}\left(\bar{g}_{1}^{c}-\psi g_{0}^{i}\right)}{\mu \delta_{2}+\Theta(1+\mu)}=\frac{(\varepsilon-\mu) \delta_{2}(1+\mu)\left(\bar{g}_{1}^{c}-\psi g_{0}^{i}\right)}{\mu \delta_{2}(1+\mu)+\mu^{2}+\delta_{1}+\left(1+\delta_{1}\right) \sigma_{\varepsilon}^{2}}, \\
& \pi_{2}=\frac{(1+\varepsilon) \delta_{2} \bar{g}_{2}^{c}}{\delta_{2} \mu+\Theta(1+\mu)}=\frac{(1+\varepsilon) \delta_{2}(1+\mu) \bar{g}_{2}^{c}}{\mu \delta_{2}(1+\mu)+\mu^{2}+\delta_{1}+\left(1+\delta_{1}\right) \sigma_{\varepsilon}^{2}}, \\
& x_{2}=\frac{(\varepsilon-\mu) \delta_{2} \bar{g}_{2}^{c}}{\delta_{2} \mu+\Theta(1+\mu)}=\frac{(\varepsilon-\mu) \delta_{2}(1+\mu) \bar{g}_{2}^{c}}{\mu \delta_{2}(1+\mu)+\mu^{2}+\delta_{1}+\left(1+\delta_{1}\right) \sigma_{\varepsilon}^{2}} .
\end{aligned}
$$

The equilibrium solutions given by (40)-(45) allow us to examine how the economy will behave under central bank opacity when the public investment is insufficiently productivity-enhancing. 
Proposition 7. If the public investment is insufficiently productivity-enhancing in the sense that $\psi<\frac{\bar{g}_{1}^{c}}{g_{0}^{i}}$, the public investments in the two periods are set to zero. Compared to the benchmark case, the tax rate and public consumption are higher and the inflation rate and output distortions lower in period 1 , and their equilibrium values are the same in period 2.

Proof. It follows straightforwardly from comparing (40)-(45) with (13)-(16).

In the present case, even though the government has no incentive to implement a positive public investment in periods 1 and 2, the effects of public investment in period 0 allow the government to increase the tax rate and public consumption in period 1 while reducing distortions. Therefore, the inflation rate and output distortions are both lower in period 1. In period 2, as the effects of past investment disappear, the government will behave exactly like in the benchmark case.

Proposition 8a. If the public investment is insufficiently productivity-enhancing in the sense that $\psi<\frac{\bar{g}_{1}^{c}}{g_{0}^{i}}$, the tax rate and public consumption in period 1 react positively to an increase in opacity if $\frac{\bar{g}_{1}^{c}}{(1+\mu) g_{0}^{i}}<\psi<\frac{\bar{g}_{1}^{c}}{g_{0}^{i}}$, and negatively if $\psi<\frac{\bar{g}_{1}^{c}}{(1+\mu) g_{0}^{i}}$. The inflation rate and output distortions in period 1 are negatively affected by an increase in opacity independently of $\psi$. In period 2, all these variables are negatively related to the degree of opacity independently of $\psi$.

Proof. It follows straightforwardly from deriving (40)-(45) with respect to $\sigma_{\varepsilon}^{2}$.

The productivity-enhancing effect of public investment in period 0 enables the government to increase the tax rate and hence public consumption in period 1 . Thus, the disciplining effect of opacity in the tax rate and the effect of public investment allow reducing the inflation rate and 
output distortions. In period 2, since the effect of past public investment disappears, all these variables will behave as in the benchmark case.

Using (42)-(45), the variances of $\pi_{t}$ and $x_{t}$ are calculated as:

$$
\begin{aligned}
& \operatorname{var}\left(\pi_{1}\right)=\operatorname{var}\left(x_{1}\right)=\frac{\left[\delta_{2}(1+\mu)\left(\bar{g}_{1}^{c}-\psi g_{0}^{i}\right)\right]^{2} \sigma_{\varepsilon}^{2}}{\left[\mu \delta_{2}(1+\mu)+\mu^{2}+\delta_{1}+\left(1+\delta_{1}\right) \sigma_{\varepsilon}^{2}\right]^{2}}, \\
& \operatorname{var}\left(\pi_{2}\right)=\operatorname{var}\left(x_{2}\right)=\frac{\left[\delta_{2}(1+\mu) \bar{g}_{t}^{c}\right]^{2} \sigma_{\varepsilon}^{2}}{\left[\delta_{2} \mu(1+\mu)+\mu^{2}+\delta_{1}+\left(1+\delta_{1}\right) \sigma_{\varepsilon}^{2}\right]^{2}} .
\end{aligned}
$$

We notice that (47) is the same than (17).

Proposition 8b. If the public investment is insufficiently productivity-enhancing in the sense that $\psi<\frac{\bar{g}_{1}^{c}}{g_{0}^{i}}$, an increase in opacity has similar but smaller effects on the variability of inflation and output gap in period 1, and identical effects in period 2 compared to the benchmark case.

Proof. Deriving (46)-(47) with respect to $\sigma_{\varepsilon}^{2}$ yields:

$$
\begin{aligned}
& \frac{\partial \operatorname{var}\left(\pi_{1}\right)}{\partial \sigma_{\varepsilon}^{2}}=\frac{\partial \operatorname{var}\left(x_{1}\right)}{\partial \sigma_{\varepsilon}^{2}}=\frac{\left[\delta_{2}(1+\mu)\left(\bar{g}_{1}^{c}-\psi g_{0}^{i}\right)\right]^{2}\left[\mu \delta_{2}(1+\mu)+\mu^{2}+\delta_{1}-\left(1+\delta_{1}\right) \sigma_{\varepsilon}^{2}\right]}{\left[\mu \delta_{2}(1+\mu)+\mu^{2}+\delta_{1}+\left(1+\delta_{1}\right) \sigma_{\varepsilon}^{2}\right]^{3}}, \\
& \frac{\partial \operatorname{var}\left(\pi_{2}\right)}{\partial \sigma_{\varepsilon}^{2}}=\frac{\partial \operatorname{var}\left(x_{2}\right)}{\partial \sigma_{\varepsilon}^{2}}=\frac{\left[\delta_{2}(1+\mu) \bar{g}_{t}^{c}\right]^{2}\left[\delta_{2} \mu(1+\mu)+\mu^{2}+\delta_{1}-\sigma_{\varepsilon}^{2}\left(1+\delta_{1}\right)\right]}{\left[\delta_{2} \mu(1+\mu)+\mu^{2}+\delta_{1}+\left(1+\delta_{1}\right) \sigma_{\varepsilon}^{2}\right]^{3}} .
\end{aligned}
$$

The above derivatives are positive if $\sigma_{\varepsilon}^{2}<\frac{\mu \delta_{2}(1+\mu)+\mu^{2}+\delta_{1}}{1+\delta_{1}}$ and vice versa. According to the poof of Proposition 3, if $\delta_{2}>\frac{\left(1+\delta_{1}\right) \mu-\left(\mu^{2}+\delta_{1}\right)}{\mu(1+\mu)}$, the only possible case is that these derivatives are positive due to the upper bound on the initial degree of opacity, i.e. $\sigma_{\varepsilon}^{2} \leq \mu$.

These results are explained by the fact that the past investment weakens the distortionary effects of the taxes in period 1 without modifying the mechanism through which the effects of opacity are transmitted to the economy. The disciplining effect of opacity dominates the direct 
effect of opacity on macroeconomic volatility only if the initial degree of opacity is sufficiently high and the weight assigned by the government to the public consumption sufficiently low. The conditions imposed on these parameters are exactly the same as in the benchmark case.

Case 2. Public investment is set to zero only in period 2

This corresponds to the case where the marginal effect of public investment on the productivity is at an intermediate level such that $\frac{\bar{g}_{1}^{c}}{g_{0}^{i}}<\psi<\frac{\bar{g}_{1}^{c}+\sqrt{\left(\bar{g}_{1}^{c}\right)^{2}+4 g_{0}^{i} \bar{g}_{2}^{c}}}{2 g_{0}^{i}}$. This is equivalent to have simultaneously $\psi g_{0}^{i}-\bar{g}_{1}^{c}>0$ and $\psi^{2} g_{0}^{i}-\psi \bar{g}_{1}^{c}-\bar{g}_{2}^{c}<0$. Thus, the interior solution of public investment in period 1 is positive, i.e. $g_{1}^{i}=\psi g_{0}^{i}-\bar{g}_{1}^{c}>0$ and that in period 2 is negative, i.e. $g_{2}^{i}=\psi^{2} g_{0}^{i}-\psi \bar{g}_{1}^{c}-\bar{g}_{2}^{c}=\psi g_{1}^{i}-\bar{g}_{2}^{c}<0$. Setting $g_{2}^{i}=0$ implies that $\frac{\partial L_{t}^{G}}{\partial g_{2}^{i}}>0$, i.e. a decrease in $g_{2}^{i}$ under zero will improve the social welfare. Using $g_{2}^{i}=0$ and the first-order conditions (20)-(22), we obtain:

$$
\begin{aligned}
& \tau_{1}=\frac{-\left(\delta_{2}+\Theta+\beta_{G} \psi^{2} \Theta\right)\left(\pi_{1}^{e}-\psi g_{0}^{i}\right)+\beta_{G} \psi\left[\delta_{2} \pi_{2}^{e}+\psi \delta_{2} \bar{g}_{1}^{c}+\delta_{2} \bar{g}_{2}^{c}\right]}{\left(\Theta+\delta_{2}\right)\left(1+\beta_{G} \psi^{2}\right)}, \\
& g_{1}^{i}=\frac{\beta_{G} \psi\left(\pi_{2}^{e}+\bar{g}_{2}^{c}\right)-\left(\pi_{1}^{e}-\psi g_{0}^{i}\right)-\bar{g}_{1}^{c}}{\left(1+\beta_{G} \psi^{2}\right)}, \\
& \tau_{2}=\frac{\left[\left(\Theta+\delta_{2}\right) \beta_{G} \psi^{2}+\delta_{2}\right] \bar{g}_{2}^{c}+\Theta \psi\left(\psi g_{0}^{i}-\pi_{1}^{e}\right)-\Theta \pi_{2}^{e}-\Theta \psi \bar{g}_{1}^{c}}{\left(\Theta+\delta_{2}\right)\left(1+\beta_{G} \psi^{2}\right)} .
\end{aligned}
$$

Substituting $\tau_{1}, g_{1}^{i}$ and $\tau_{2}$ respectively given by (48)-(50) into (18), we obtain:

$$
\pi_{1}^{e}=\frac{\beta_{G} \delta_{2} \psi\left(-\psi^{2} g_{0}^{i}+\psi \bar{g}_{1}^{c}+\bar{g}_{2}^{c}\right)}{\left(1+\beta_{G} \psi^{2}\right)\left[\delta_{2} \mu+\Theta(1+\mu)\right]}
$$




$$
\pi_{2}^{e}=\frac{\delta_{2}\left(-\psi^{2} g_{0}^{i}+\psi \bar{g}_{1}^{c}+\bar{g}_{2}^{c}\right)}{\left(1+\beta_{G} \psi^{2}\right)\left[\delta_{2} \mu+\Theta(1+\mu)\right]} .
$$

Since $\psi^{2} g_{0}^{i}-\psi \bar{g}_{1}^{c}-\bar{g}_{2}^{c}<0$, we have $\pi_{1}^{e}, \pi_{2}^{e}>0$.

Substituting the above solutions of $\pi_{1}^{e}$ and $\pi_{2}^{e}$ into (48)-(50) yields:

$$
\begin{aligned}
& g_{1}^{i}=\frac{\beta_{G} \psi \bar{g}_{2}^{c}+\psi g_{0}^{i}-\bar{g}_{1}^{c}}{1+\beta_{G} \psi^{2}}, \\
& \tau_{1}=\frac{\psi \Theta(1+\mu)\left(1+\beta_{G} \psi^{2}\right) g_{0}^{i}+\mu \delta_{2} \psi g_{0}^{i}+\beta_{G} \delta_{2} \psi \mu\left(\psi \bar{g}_{1}^{c}+\bar{g}_{2}^{c}\right)}{\left(1+\beta_{G} \psi^{2}\right)\left[\delta_{2} \mu+\Theta(1+\mu)\right]}, \\
& \tau_{2}=\frac{\left[\delta_{2} \mu\left(1+\beta_{G} \psi^{2}\right)+\beta_{G} \psi^{2} \Theta(1+\mu)\right] \bar{g}_{2}^{c}+\Theta \psi(1+\mu)\left(\psi g_{0}^{i}-\bar{g}_{1}^{c}\right)}{\left(1+\beta_{G} \psi^{2}\right)\left[\delta_{2} \mu+\Theta(1+\mu)\right]} .
\end{aligned}
$$

Using (3), (53)-(54) and $g_{2}^{i}=0$, the public consumption in periods 1 and 2 is:

$$
\begin{aligned}
& g_{1}^{c}=\frac{\left[\delta_{2} \mu\left(1+\beta_{G} \psi^{2}\right)+\Theta(1+\mu)\right] \bar{g}_{1}^{c}+\beta_{G} \psi \Theta(1+\mu)\left(\psi^{2} g_{0}^{i}-\bar{g}_{2}^{c}\right)}{\left(1+\beta_{G} \psi^{2}\right)\left[\delta_{2} \mu+\Theta(1+\mu)\right]}, \\
& g_{2}^{c}=\frac{\left[\delta_{2} \mu\left(1+\beta_{G} \psi^{2}\right)+\beta_{G} \psi^{2} \Theta(1+\mu)\right] \bar{g}_{2}^{c}+\Theta \psi(1+\mu)\left(\psi g_{0}^{i}-\bar{g}_{1}^{c}\right)}{\left(1+\beta_{G} \psi^{2}\right)\left[\delta_{2} \mu+\Theta(1+\mu)\right]} .
\end{aligned}
$$

Finally, using (1), (18), (51)-(53) and (55), we get the inflation rate and output gap in periods 1 and 2:

$$
\begin{aligned}
& \pi_{1}=\frac{(1+\varepsilon) \beta_{G} \delta_{2} \psi\left(-\psi^{2} g_{0}^{i}+\psi \bar{g}_{1}^{c}+\bar{g}_{2}^{c}\right)}{\left(1+\beta_{G} \psi^{2}\right)\left[\delta_{2} \mu+\Theta(1+\mu)\right]}, \\
& x_{1}=\frac{(\varepsilon-\mu) \beta_{G} \delta_{2} \psi\left(-\psi^{2} g_{0}^{i}+\psi \bar{g}_{1}^{c}+\bar{g}_{2}^{c}\right)}{\left(1+\beta_{G} \psi^{2}\right)\left[\delta_{2} \mu+\Theta(1+\mu)\right]}, \\
& \pi_{2}=\frac{(1+\varepsilon) \delta_{2}\left(-\psi^{2} g_{0}^{i}+\psi \bar{g}_{1}^{c}+\bar{g}_{2}^{c}\right)}{\left(1+\beta_{G} \psi^{2}\right)\left[\delta_{2} \mu+\Theta(1+\mu)\right]} \\
& x_{2}=\frac{(\varepsilon-\mu) \delta_{2}\left(-\psi^{2} g_{0}^{i}+\psi \bar{g}_{1}^{c}+\bar{g}_{2}^{c}\right)}{\left(1+\beta_{G} \psi^{2}\right)\left[\delta_{2} \mu+\Theta(1+\mu)\right]} .
\end{aligned}
$$


Using (58)-(61), the variances of $\pi_{t}$ and $x_{t}$ are calculated as:

$$
\begin{aligned}
& \operatorname{var}\left(\pi_{1}\right)=\operatorname{var}\left(x_{1}\right)=\frac{\left[\beta_{G} \delta_{2} \psi\left(-\psi^{2} g_{0}^{i}+\psi \bar{g}_{1}^{c}+\bar{g}_{2}^{c}\right)\right]^{2} \sigma_{\varepsilon}^{2}}{\left\{\left(1+\beta_{G} \psi^{2}\right)\left[\delta_{2} \mu+\Theta(1+\mu)\right]\right\}^{2}}, \\
& \operatorname{var}\left(\pi_{2}\right)=\operatorname{var}\left(x_{2}\right)=\frac{\left[\delta_{2}\left(-\psi^{2} g_{0}^{i}+\psi \bar{g}_{1}^{c}+\bar{g}_{2}^{c}\right)\right]^{2} \sigma_{\varepsilon}^{2}}{\left\{\left(1+\beta_{G} \psi^{2}\right)\left[\delta_{2} \mu+\Theta(1+\mu)\right]\right\}^{2}} .
\end{aligned}
$$

In the following, we compare the equilibrium solutions given by (53)-(61) with these obtained in the first case of the corner solutions (40)-(45) and with the benchmark solutions (13)(15). Furthermore, we compare the macroeconomic volatility obtained in the present case with these observed in the benchmark solution (17) and in the first case of the corner solutions (46)(47).

Proposition 9a. If the public investment is relatively productivity-enhancing in the sense that $\frac{\bar{g}_{1}^{c}}{g_{0}^{i}}<\psi<\frac{\bar{g}_{1}^{c}+\sqrt{\left(\bar{g}_{1}^{c}\right)^{2}+4 g_{0}^{i} \bar{g}_{2}^{c}}}{2 g_{0}^{i}}$, the optimal level of public investment is positive in period 1 and zero in period 2. Compared to the benchmark case, the tax rate and public consumption are higher in two periods, the inflation rate and output distortions are lower (higher) in period 1 if $\psi^{2} g_{0}^{i}-\psi \bar{g}_{1}^{c}<\bar{g}_{2}^{c}<\frac{\bar{g}_{1}^{c}}{\beta_{G} \psi}+\psi^{2} g_{0}^{i}$ (if $\bar{g}_{2}^{c}>\frac{\bar{g}_{1}^{c}}{\beta_{G} \psi}+\psi^{2} g_{0}^{i}$ ) while they are always lower in period 2.

Proof. See Appendix A, part I.

In the second case of the corner solutions, a positive public investment is implemented in period 1 but not in period 2. Compared to the benchmark case, the government can increase the tax rate and public consumption in periods 1 and 2 while reducing distortions due to the effects of public investment in periods 0 and 1 . Therefore, the inflation rate and output distortions are both lower in period 1 if the public consumption target of period 2 is not too higher. In effect, if the latter is too high, the intertemporal trade-off will incite the government to increase the tax rate in the way that it can invest more in period 1, leading to higher inflation rate and output 
distortions in this period. In period 2, as the public investment in period 1 has a positive effect on the production in period 2, the government reduces output distortions and this incites the central bank to reduce the inflation rate.

Proposition 9b. Compared to the case where $\psi<\frac{\bar{g}_{1}^{c}}{g_{0}^{i}}$, the tax rate is higher in two periods. The public consumption is higher, and the inflation rate and output distortions lower in period 1 only if the target of public consumption in period 2 is not too high. The public consumption is higher, and the inflation rate and output distortions lower in the period 2.

Proof. See Appendix A, part II.

The second case of the corner solutions is intermediate between the first case (where the government does not invest in periods 1 and 2) and the case of the interior solutions (where the government has incentive to invest in both periods). The productivity-enhancing effect of past investment urges the government to increase the public consumption in period 1, but this effect could be dominated by the effect of intertemporal trade-off. More precisely, if the public consumption target of period 2 is too high, the government will lower the public consumption in period 1 to implement a higher level of public investment allowing it to recover more fiscal revenue in the period 2.

Proposition 10a. If the public investment is relatively productivity-enhancing in the sense that $\frac{\bar{g}_{1}^{c}}{g_{0}^{i}}<\psi<\frac{\bar{g}_{1}^{c}+\sqrt{\left(\bar{g}_{1}^{c}\right)^{2}+4 g_{0}^{i} \bar{g}_{2}^{c}}}{2 g_{0}^{i}}$ such that the public investment is set to zero only in period 2, the public investment in period 1 is not affected by central bank opacity, while the tax rate, public consumption, inflation rate and output distortions in two periods are negatively affected by an increase in opacity. 
Proof. It follows straightforwardly from deriving (53)-(61) with respect to $\sigma_{\varepsilon}^{2}$, taking into account that $\Theta \approx \frac{\mu^{2}+\delta_{1}}{(1+\mu)^{2}}+\frac{\left(1+\delta_{1}\right)}{(1+\mu)^{2}} \sigma_{\varepsilon}^{2}$ and $\psi^{2} g_{0}^{i}-\psi \bar{g}_{1}^{c}-\bar{g}_{2}^{c}<0$.

In the second case of the corner solutions, as in the benchmark case, the disciplining effect of opacity on the tax rate allows the reduction of the output distortions and hence of the inflation rate. However, public investments are independent of central bank preferences and hence of central bank opacity. This is because the public investment allows the reduction of the output distortions, and the government has to trade-off between its current consumption and current investment, something that affects the future public consumption. Therefore, the choice of public investment depends only on the parameter representing the marginal effect of public investment, on the supply function and the parameters characterizing the government preferences.

Proposition 10b. If the public investment is relatively productivity-enhancing in the sense that $\frac{\bar{g}_{1}^{c}}{g_{0}^{i}}<\psi<\frac{\bar{g}_{1}^{c}+\sqrt{\left(\bar{g}_{1}^{c}\right)^{2}+4 g_{0}^{i} \bar{g}_{2}^{c}}}{2 g_{0}^{i}}$, an increase in opacity has similar but smaller effects on the variability of inflation and output gap in period 1 (except when the public consumption target in period 2 is too high, i.e. $\left.\bar{g}_{2}^{c}>\frac{\bar{g}_{1}^{c}}{\beta_{G} \psi}+\psi^{2} g_{0}^{i}\right)$ and identical effects in period 2, compared to the benchmark.

Proof. See Appendix B.

As discussed above, the public investments in periods 0 and 1 attenuate the distortionary effects of the taxes in periods 1 and 2 but do not modify the mechanism through which the effects of opacity are transmitted to the economy. As in the benchmark case, an increase in opacity could reduce the macroeconomic volatility only when the direct effect of opacity is dominated by the fiscal disciplining effect of opacity. This is possible only when the initial degree of opacity is sufficiently high and the weight assigned by the government to the public consumption 
sufficiently low, with the conditions imposed on these parameters being the same as in the benchmark case.

Our findings suggest that when the public investment is highly productivity-enhancing, the government will have another free policy instrument that can be used efficiently to neutralize the distortionary effects of taxes necessary for financing public expenditures. In this case, central bank opacity has no effect on the macroeconomic performance and volatility. However, as shown by the corner solutions, when the public investment is not sufficiently productivity-enhancing, the government cannot use it to completely counterbalance the distortionary effects of taxes. Therefore, the level of output distortions and the effects of opacity in the macroeconomic performance and volatility will situate between these found in the benchmark case and these in the case where the public investment is highly productivity-enhancing.

The benchmark case suggests that an increase in opacity improves the macroeconomic performance by reducing the tax rate, and hence the inflation rate and output distortions through the fiscal disciplining effect. It could reduce the macroeconomic volatility when the direct effect of opacity is dominated by the fiscal disciplining effect, i.e. if the initial degree of opacity is sufficiently high and the weight assigned by the government to the target of public consumption low enough. Under these conditions, there is clearly a case for central bank opacity. If the weight assigned by the government to the target of public consumption is high enough, then there is a trade-off between macroeconomic performance and volatility, because an increase in opacity induces lower inflation rate and output distortions but higher macroeconomic volatility. The trade-off is cancelled if the public investment is highly productivity-enhancing, since the government could neutralize the distortionary effects of the taxes. However, when the public investment is insufficiently productivity-enhancing, the implications of the benchmark case are still valid even though the effects of opacity on the macroeconomic performance and volatility 
could be weakened by the productivity-enhancing effects of public investment in the past and/or in period 1.

Our previous results are obtained by assuming a Stackelberg game, a budget constraint excluding debt-financing and a particular timing sequence concerning the effect of productivityenhancing public investment. A robust check of our results would need to consider the implications of alternative assumptions about these points. In the following, without giving full algebraic developments, we just provide some intuitions about how our findings could be affected if these alternative assumptions are adopted.

Regarding the timing of the fiscal policy innovations, it is to notice that in equation (1) which models the link between fiscal aggregates and the output gap, distortionary taxes enter such equation contemporaneously, i.e. an immediate impact on the business cycle is allowed. In contrast, fiscal expenditures through productivity-enhancing public investment exert their positive impact on the business cycle with a one-period lag. Such time discrepancy can be explained by the fact that the achievement of such investment may take a delay and the government pays the contractors of public investment before its achievement under a fiscal rule which asks each government to use current fiscal revenue to finance current public investment even though the later has positive effect on next period revenue.

However, one might think of fiscal expenditures planned and implemented in advance on the basis of an expected amount of revenues collected later on. Under this interpretation, it would call for the debt-financing of public investment in order to share the burden of its cost over time, leading to the presence of real public debt in the economy. Therefore, one possible extension of the present model is to consider, following Ismihan and Ozkan (2007), a government budget constraint which creates the link between the fiscal and monetary policies: 


$$
g_{t}^{i}+g_{t}^{c}+\left(1+r_{t-1}\right) d_{t-1}=k \pi_{t}+\tau_{t}+d_{t}
$$

where $k$ is the real holdings of base money as share of output, $d_{t-1}$ denotes the amount of singleperiod indexed public debt issued (as a ratio of output) in period $t-1$ and to be re-paid in period $t, r_{t-1}$ represents the rate of interest at which it is borrowed, $d_{t}$ is the new debt issue in period $t$. Such an extension implies that we have to modify the budget constraint in the benchmark case to include as well the seigneuriage revenue:

$$
g_{t}^{i}+g_{t}^{c}=k \pi_{t}+\tau_{t}
$$

Taking into account of public debt or/and seigniorage revenue complicate considerably the algebraic analysis. Consider first the benchmark Stackelberg equilibrium with the budget constraint (66). The seigeneuriage revenue is an alternative source of financing which can substitute the tax revenues since, for a given public expenditures, a higher seigeneuriage revenue will allow the government to reduce the distortionary tax rate. Therefore, the central bank has incentive to let inflation rate be higher in order to reduce the distortions induced by distortionary taxes. On the other hand, by increasing the tax rate, the government could induce a higher inflation in order to boost total fiscal revenue. In this framework, the inclusion of seigneuriage revenue could decrease the disciplining effect of central bank opacity. The final effects of central bank opacity will be ambiguous and depend on the structural parameters of the model.

In the case where the policymaker has access to borrowing from the public in order to finance public investment, it has two supplementary (intertemporal) instruments at its disposal, public investment and public debt. The first can be utilized to improve future output prospects and the second to spread the cost of financing public spending over time. In effect, the fiscal authority's optimization now requires balancing the intertemporal consequences of both $g_{1}^{i}$ and $d_{1}$ in 
addition to equalizing the marginal welfare losses from different sources of taxation $\left(\pi_{t}\right.$ and $\left.\tau_{t}\right)$. In opposite to an increase in public investment, a rise in the first period's public borrowing has a favourable effect on macroeconomic performance (higher inflation rate, output gap and current spending gap) but an unfavourable effect on the second period's one. In effect, the presence of sufficiently productivity-enhancing public investment opportunities, i.e. when $\psi$ is higher enough, enables the policymaker to finance popularity-enhancing public consumption in both periods with the help of intertemporal instruments $\left(g_{1}^{i}\right.$ and $\left.d_{1}\right)$ without hampering output and inflation performance (Ismihan and Ozkan, 2007). In this framework, central bank opacity will have negative effects on social welfare given the choice of public debt, public investment and tax rate. As we have argued before, since the government has more than one instrument at its disposal, it could generally neutralize the effect of central bank opacity on the Stackelberg equilibrium if the public investment is sufficiently productivity-enhancing. In the other cases, the effects of central bank opacity will persist but will be less than at the benchmark equilibrium.

An alternative assumption about the timing of the fiscal policy innovations, i.e. the current public investment has productivity-enhancing effects on current supply, could justify better the nonexistence of public debt in the budget constraint given by equation (3). If government expenditures entered equation (1) contemporaneously, without giving the detailed algebra which will be quite simple to do, we conjecture that the general results of the model will not be significantly modified. There will not be any intertemporal but just intratemporal arbitrage between public investment, tax rate and public consumption. As the government will be able to neutralize the effects of distortions induced by the taxes when the public investment is sufficiently productivity-enhancing, the effects of central bank opacity which act through the 
economic distortions induced by taxes will again disappear. In the other case, the effects of central bank opacity will be identical to these at the benchmark equilibrium.

Our main findings and previous discussions are based on the assumption that the government is the Stackelberg leader and the central bank the Stackelberg follower. This corresponds to the case where the government sets its fiscal policy once a year, say at the beginning of the period, and the central bank makes monetary policy decisions on numerous occasions during that year. However, it is possible that important policy decisions also occur contemporaneously. One would like to understand how the results would change if the assumption on the timing of the strategic game is modified by allowing the government and the central bank to move simultaneously in a Nash game. The basic difference in terms of results will appear in the benchmark model's Nash equilibrium. Central bank opacity is likely to induce higher inflation expectations and hence higher inflation rate. The reason is that, in the Nash game, the government does not make any commitment as in the Stackelberg game. The central bank will doubt if opacity has any fiscal disciplining effects and will tend to consider that the fiscal authority will not restrain its public consumption and taxes. As a result, the fiscal authority will have incentive to restrict as less as possible its taxes and public consumption. At the equilibrium, the fiscal disciplining effect of central bank opacity would be present only if the government attributes a too high relative weight to the public consumption. The direct effect of central bank opacity will dominate the fiscal disciplining effect of opacity if the latter exists. Central bank opacity will always induce higher inflation rate and lower output gap in the presence of distortionary taxes, leading to higher inflation and output volatility. Whatever is the fiscal (un)disciplining effect in the Nash equilibrium, the introduction of productivity-enhancing public investment will give the government a supplementary policy instrument to fully neutralize the direct and indirect effects of central bank opacity if the marginal productivity of public investment is sufficiently high. In 
the other cases, central bank opacity could still have undesirable effects on the macroeconomic performance.

\section{Conclusion}

In a two-period model where productivity-enhancing public investment could improve future growth potential, we have examined the interaction between central bank transparency and fiscal policy and the resulting effects on macroeconomic performance and volatility. In the framework of the Stackelberg equilibrium, where the government is the first mover and the central bank the follower, we have shown that the effects of central bank's opacity (or lack of transparency) depend on the marginal effect of public investment.

In the benchmark case (without productivity-enhancing public investment), central bank's opacity reduces the inflation rate, tax rate, public consumption and output distortions when the direct effect of opacity is dominated by the fiscal disciplining effect of opacity. The latter condition is verified when the weight assigned to the public consumption is low enough, the central bank is quite populist, and the initial degree of opacity is high enough. We have demonstrated that the government's optimal choice of tax rate and public investment, when the public investment is highly productivity-enhancing, eliminate the effects of distortionary taxation and fully counterbalance both the direct and the fiscal-disciplining effects of opacity at the level and variability of inflation and output gap.

However, in the intermediate cases, where the public investment is insufficiently or relatively productivity-enhancing, the effects of opacity would be between these predicted by the benchmark model. Even though the effects of opacity on the macroeconomic performance and 
volatility could be weakened by the productivity-enhancing effects of public investment, the implications of the benchmark case, regarding the effects of opacity, will be valid again.

Finally, the present study can be extended into different directions by considering, for example, a Nash game structure, a budget constraint including seigneuriage revenue and public debt used to finance the public investment, and/or the contemporary effect of public investment. Some of these extensions could affect significantly the benchmark equilibrium and/or the transmission mechanism of monetary and fiscal policy in the full model. However, we conjecture that our findings concerning the neutralization of the effects of central bank opacity when the public investment is sufficiently productivity-enhancing are robust to these alternative assumptions.

\section{Appendix A: Proof of Propositions 9a and 9b}

Denote the solutions in the benchmark case with a super index " $b$ ", the first corner solutions with a super index " $f c$ " and the second-case corner solutions with a super index "sc". The parameter $\psi$ is also indexed so that we have in the first-case of corner solutions $\frac{\bar{g}_{1}^{c}}{g_{0}^{i}}<\psi^{s c}<\frac{\bar{g}_{1}^{c}+\sqrt{\left(\bar{g}_{1}^{c}\right)^{2}+4 g_{0}^{i} \bar{g}_{2}^{c}}}{2 g_{0}^{i}}$, which can be decomposed as $\quad \psi^{s c} g_{0}^{i}-\bar{g}_{1}^{c}>0 \quad$ and $\psi^{s c 2} g_{0}^{i}-\psi^{s c} \bar{g}_{1}^{c}-\bar{g}_{2}^{c}<0$, where $\psi^{s c 2}$ stands for $\left(\psi^{s c}\right)^{2}$, and we have in the second case of corner solutions, $\psi^{f c} g_{0}^{i}-\bar{g}_{1}^{c}<0$. Furthermore, we have $\psi^{s c}-\psi^{f_{c}}>0$.

\section{Part I: Second case of corner solutions versus the benchmark case}

Comparing the second-case corner solutions (54)-(61) with the benchmark solutions (13)-(16), and using the condition $\frac{\bar{g}_{1}^{c}}{g_{0}^{i}}<\psi^{s c}<\frac{\bar{g}_{1}^{c}+\sqrt{\left(\bar{g}_{1}^{c}\right)^{2}+4 g_{0}^{i} \bar{g}_{2}^{c}}}{2 g_{0}^{i}}$, we obtain: 


$$
\begin{aligned}
& \tau_{1}^{s c}-\tau_{1}^{b}=\frac{\psi^{s c} \Theta(1+\mu)\left(1+\beta_{G} \psi^{s c 2}\right) g_{0}^{i}+\mu \delta_{2}\left(\psi^{s c} g_{0}^{i}-\bar{g}_{1}^{c}\right)+\beta_{G} \delta_{2} \psi^{s c} \mu \bar{g}_{2}^{c}}{\left(1+\beta_{G} \psi^{s c 2}\right)\left[\delta_{2} \mu+\Theta(1+\mu)\right]}>0, \\
& g_{1}^{c s c}-g_{1}^{c b}=\frac{\Theta(1+\mu) \bar{g}_{1}^{c}+\beta_{G} \psi^{s c} \Theta(1+\mu)\left(\psi^{s c 2} g_{0}^{i}-\bar{g}_{2}^{c}\right)}{\left(1+\beta_{G} \psi^{s c 2}\right)\left[\delta_{2} \mu+\Theta(1+\mu)\right]}>0, \\
& \pi_{1}^{s c}-\pi_{1}^{b}=\frac{(1+\varepsilon) \delta_{2}\left[\beta_{G} \psi^{s c}\left(-\psi^{s c 2} g_{0}^{i}+\bar{g}_{2}^{c}\right)-\bar{g}_{1}^{c}\right]}{\left(1+\beta_{G} \psi^{s c 2}\right)\left[\delta_{2} \mu+\Theta(1+\mu)\right]}, \\
& x_{1}^{s c}-x_{1}^{b}=\frac{(\mu-\varepsilon) \delta_{2}\left(\beta_{G} \psi^{s c 3} g_{0}^{i}-\beta_{G} \psi^{s c} \bar{g}_{2}^{c}+\bar{g}_{1}^{c}\right)}{\left(1+\beta_{G} \psi^{s c 2}\right)\left[\delta_{2} \mu+\Theta(1+\mu)\right]}>0, \\
& \tau_{2}^{s c}-\tau_{2}^{b}=g_{2}^{c s c}-g_{2}^{c b}=\frac{\beta_{G} \psi^{s c 2} \Theta(1+\mu) \bar{g}_{2}^{c}+\Theta \psi^{s c}(1+\mu)\left(\psi^{s c} g_{0}^{i}-\bar{g}_{1}^{c}\right)}{\left(1+\beta_{G} \psi^{s c 2}\right)\left[\delta_{2} \mu+\Theta(1+\mu)\right]}>0, \\
& \pi_{2}^{s c}-\pi_{2}^{b}=\frac{-(1+\varepsilon) \delta_{2}\left[\psi^{s c}\left(\psi^{s c} g_{0}^{i}-\bar{g}_{1}^{c}\right)+\beta_{G} \psi^{s c 2} \bar{g}_{2}^{c}\right]}{\left(1+\beta_{G} \psi^{s c 2}\right)\left[\Theta+\mu\left(\Theta+\delta_{2}\right)\right]}<0, \text { since } \psi^{s c} g_{0}^{i}-\bar{g}_{1}^{c}>0, \\
& x_{2}^{s c}-x_{2}^{b}=\frac{(\mu-\varepsilon) \delta_{2}\left[\psi^{s c}\left(\psi^{s c} g_{0}^{i}-\bar{g}_{1}^{c}\right)+\beta_{G} \psi^{s c 2} \bar{g}_{2}^{c}\right]}{\left(1+\beta_{G} \psi^{s c 2}\right)\left[\Theta+\mu\left(\Theta+\delta_{2}\right)\right]}>0, \text { since } \psi^{s c} g_{0}^{i}-\bar{g}_{1}^{c}>0 .
\end{aligned}
$$

We obtain $\pi_{1}^{s c}-\pi_{1}^{b}<0$ and $x_{1}^{s c}-x_{1}^{b}>0$ if $\psi^{s c 2} g_{0}^{i}-\psi^{s c} \bar{g}_{1}^{c}<\bar{g}_{2}^{c}<\frac{\bar{g}_{1}^{c}}{\beta_{G} \psi^{s c}}+\psi^{s c 2} g_{0}^{i}$, and $\pi_{1}^{s c}-\pi_{1}^{b}>0$ and $x_{1}^{s c}-x_{1}^{b}<0$ if $\bar{g}_{2}^{c}>\frac{\bar{g}_{1}^{c}}{\beta_{G} \psi^{s c}}+\psi^{s c 2} g_{0}^{i}$

Part II: Second case of corner solutions versus the first case

Solutions (40)-(45) and (54)-(61) are indexed according to the aforementioned conventions. Comparing them yields:

$$
\begin{aligned}
& \tau_{1}^{s c}-\tau_{1}^{f c}=\frac{\left(\psi^{s c}-\psi^{f c}\right)\left(1+\beta_{G} \psi^{s c 2}\right)(1+\mu) \Theta g_{0}^{i}+\mu \delta_{2}\left(\psi^{s c} g_{0}^{i}-\bar{g}_{1}^{c}\right)+\beta_{G} \delta_{2} \psi^{s c} \mu \bar{g}_{2}^{c}}{\left(1+\beta_{G} \psi^{s c 2}\right)\left[\delta_{2} \mu+\Theta(1+\mu)\right]}>0, \\
& g_{1}^{c s c}-g_{1}^{c f c}=\frac{\left.\Theta(1+\mu)\left[\left(\bar{g}_{1}^{c}-\psi^{f c} g_{0}^{i}\right)-\beta_{G} \psi^{s c} \bar{g}_{2}^{c}\right)\right]+\beta_{G} \psi^{s c 2} \Theta(1+\mu) g_{0}^{i}\left(\psi^{s c}-\psi^{f c}\right)}{\left(1+\beta_{G} \psi^{s c 2}\right)\left[\delta_{2} \mu+\Theta(1+\mu)\right]},
\end{aligned}
$$




$$
\begin{aligned}
& \pi_{1}^{s c}-\pi_{1}^{f c}=\frac{(1+\varepsilon) \delta_{2}\left[\left(\psi^{f c} g_{0}^{i}-\bar{g}_{1}^{c}\right)+\beta_{G} \psi^{s c 2}\left(\psi^{f c}-\psi^{s c}\right) g_{0}^{i}\right]+(1+\varepsilon) \beta_{G} \delta_{2} \psi^{s c} \bar{g}_{2}^{c}}{\left(1+\beta_{G} \psi^{s c 2}\right)\left[\delta_{2} \mu+\Theta(1+\mu)\right]}, \\
& x_{1}^{s c}-x_{1}^{f c}=\frac{(\varepsilon-\mu) \delta_{2}\left[\left(\psi^{f c} g_{0}^{i}-\bar{g}_{1}^{c}\right)+\beta_{G} \psi^{s c 2}\left(\psi^{f c}-\psi^{s c}\right) g_{0}^{i}\right]+(\varepsilon-\mu) \beta_{G} \delta_{2} \psi^{s c} \bar{g}_{2}^{c}}{\left(1+\beta_{G} \psi^{s c 2}\right)\left[\delta_{2} \mu+\Theta(1+\mu)\right]}, \\
& \tau_{2}^{s c}-\tau_{2}^{f c}=g_{2}^{c s c}-g_{2}^{c f c}=\frac{\beta_{G} \psi^{s c 2} \Theta(1+\mu) \bar{g}_{2}^{c}+\Theta \psi^{s c}(1+\mu)\left(\psi^{s c} g_{0}^{i}-\bar{g}_{1}^{c}\right)}{\left(1+\beta_{G} \psi^{s c 2}\right)\left[\delta_{2} \mu+\Theta(1+\mu)\right]}>0 . \\
& \pi_{2}^{s c}-\pi_{2}^{f c}=\frac{-(1+\varepsilon) \delta_{2} \psi^{s c}\left(\psi^{s c} g_{0}^{i}-\bar{g}_{1}^{c}\right)-(1+\varepsilon) \beta_{G} \delta_{2} \psi^{s c 2} \bar{g}_{2}^{c}}{\left(1+\beta_{G} \psi^{s c 2}\right)\left[\Theta+\mu\left(\Theta+\delta_{2}\right)\right]}<0, \\
& x_{2}^{s c}-x_{2}^{f c}=\frac{-(\varepsilon-\mu) \delta_{2} \psi^{s c}\left(\psi^{s c} g_{0}^{i}-\bar{g}_{1}^{c}\right)-(\varepsilon-\mu) \delta_{2} \beta_{G} \psi^{s c 2} \bar{g}_{2}^{c}}{\left(1+\beta_{G} \psi^{s c 2}\right)\left[\Theta+\mu\left(\Theta+\delta_{2}\right)\right]}>0 .
\end{aligned}
$$

Using $\psi^{f c} g_{0}^{i}-\bar{g}_{1}^{c}<0$ and $\psi^{s c}-\psi^{f c}>0$, we obtain $g_{1}^{\mathrm{csc}}-g_{1}^{c f c}>0, \quad \pi_{1}^{s c}-\pi_{1}^{f c}<0$ and $x_{1}^{s c}-x_{1}^{f c}>0$ if $\bar{g}_{2}^{c}<\frac{\left(\bar{g}_{1}^{c}-\psi^{f c} g_{0}^{i}\right)+\beta_{G} \psi^{s c 2} g_{0}^{i}\left(\psi^{s c}-\psi^{f c}\right)}{\beta_{G} \psi^{s c}}$ and vice versa.

\section{Appendix B. Proof of Proposition $10 \mathrm{~b}$.}

Using $\Theta \approx \frac{\mu^{2}+\delta_{1}}{(1+\mu)^{2}}+\frac{\left(1+\delta_{1}\right)}{(1+\mu)^{2}} \sigma_{\varepsilon}^{2}$, and deriving $\operatorname{var}\left(\pi_{1}\right)$ and $\operatorname{var}\left(x_{1}\right)$ given by $(63)$, and $\operatorname{var}\left(\pi_{2}\right)$ and $\operatorname{var}\left(x_{2}\right)$ given by (64) with respect to $\sigma_{\varepsilon}^{2}$ yields:

$$
\begin{aligned}
& \frac{\partial \operatorname{var}\left(\pi_{1}\right)}{\partial \sigma_{\varepsilon}^{2}}=\frac{\partial \operatorname{var}\left(x_{1}\right)}{\partial \sigma_{\varepsilon}^{2}}=\frac{\left[\delta_{2} \mu(1+\mu)+\mu^{2}+\delta_{1}-\left(1+\delta_{1}\right) \sigma_{\varepsilon}^{2}\right]\left(1+\beta_{G} \psi^{2}\right)\left[\beta_{G} \delta_{2} \psi\left(-\psi^{2} g_{0}^{i}+\psi \bar{g}_{1}^{c}+\bar{g}_{2}^{c}\right)\right]^{2}}{(1+\mu)\left\{\left(1+\beta_{G} \psi^{2}\right)\left[\delta_{2} \mu+\Theta(1+\mu)\right]\right\}^{3}}, \\
& \frac{\partial \operatorname{var}\left(\pi_{2}\right)}{\partial \sigma_{\varepsilon}^{2}}=\frac{\partial \operatorname{var}\left(x_{2}\right)}{\partial \sigma_{\varepsilon}^{2}}=\frac{\left[\delta_{2} \mu(1+\mu)+\mu^{2}+\delta_{1}-\sigma_{\varepsilon}^{2}\left(1+\delta_{1}\right)\right]\left(1+\beta_{G} \psi^{2}\right)\left[\delta_{2}\left(-\psi^{2} g_{0}^{i}+\psi \bar{g}_{1}^{c}+\bar{g}_{2}^{c}\right)\right]^{2}}{(1+\mu)\left\{\left(1+\beta_{G} \psi^{2}\right)\left[\delta_{2} \mu+\Theta(1+\mu)\right]\right\}^{3}}
\end{aligned}
$$

We have $\frac{\partial \operatorname{var}\left(\pi_{1}\right)}{\partial \sigma_{\varepsilon}^{2}}=\frac{\partial \operatorname{var}\left(x_{1}\right)}{\partial \sigma_{\varepsilon}^{2}}>0$ and $\frac{\partial \operatorname{var}\left(\pi_{2}\right)}{\partial \sigma_{\varepsilon}^{2}}=\frac{\partial \operatorname{var}\left(x_{2}\right)}{\partial \sigma_{\varepsilon}^{2}}>0$ if $\sigma_{\varepsilon}^{2}<\frac{\delta_{2} \mu(1+\mu)+\mu^{2}+\delta_{1}}{1+\delta_{1}}$ and vice versa. If $\frac{\delta_{2} \mu(1+\mu)+\mu^{2}+\delta_{1}}{1+\delta_{1}}>\mu$, i.e. $\delta_{2}>\frac{\left(1+\delta_{1}\right) \mu-\left(\mu^{2}+\delta_{1}\right)}{\mu(1+\mu)}$, the only case possible is that these derivatives are 
positive due to the upper bound on the initial degree of opacity, i.e. $\sigma_{\varepsilon}^{2} \leq \mu$ (see the proof of Proposition 3).

The variance of inflation and the output gap in period 1, given by (63), is greater (smaller) than the one given by (17) in the benchmark case if $\bar{g}_{2}^{c}>\frac{\bar{g}_{1}^{c}}{\beta_{G} \psi}+\psi^{2} g_{0}^{i}$ (if $\psi^{2} g_{0}^{i}-\psi \bar{g}_{1}^{c}<\bar{g}_{2}^{c}<\frac{\bar{g}_{1}^{c}}{\beta_{G} \psi}+\psi^{2} g_{0}^{i}$, respectively). The variance of inflation and the output gap in period 2 , given by (64), is smaller than that given by (17).

\section{References:}

Aschauer, D. A. (1989), "Is public expenditure productive?" Journal of Monetary Economics 23, 177-200.

Azzimonti, Marina, Pierre-Daniel Sarte and Jorge Soares (2009), "Distortionary taxes and public investment when government promises are not enforceable," Journal of Economic Dynamics and Control, vol. 33(9), 1662-81.

Barro, Robert J. (1990), "Government Spending in a Simple Model of Endogenous Growth," Journal of Political Economy, vol. 98(5), S103-26.

Beetsma, R.M.W.J. and H. Jensen (2003), "Why money talks and wealth wispers: Monetary uncertainty and mystique. A comment," Journal of Money, Credit, and Banking 35, 129-36.

Blinder, Alan S. (1998), Central Banking in Theory and Practice. MIT Press, Cambridge, MA.

Brainard, W. (1967), "Uncertainty and the effectiveness of policy," American Economic Review 57 (2), 411-25.

Cashin, P. (1995), "Government Spending, Taxes, and Economic Growth," IMF Staff Papers, Vol. 42, No. 2, 237-69.

Cavalcanti Ferreira, Pedro (1999), "Inflationary financing of public investment and economic growth," Journal of Economic Dynamics and Control, Volume 23, Issue 4, 539-63.

Chortareas, G., D. Stasavage, and G. Sterne (2002), "Does it pay to be transparent? International evidence from central bank forecasts," Federal Reserve Bank of St. Louis Review 84, iss. 4, 99117.

Ciccarone, Giuseppe, Enrico Marchetti and Giovanni Di Bartolomeo (2007), "Unions, fiscal policy and central bank transparency," The Manchester School, vol. 75, 617-33.

Cukierman, Alex and Allan H. Meltzer (1986), "A Theory of Ambiguity, Credibility, and Inflation under Discretion and Asymmetric Information," Econometrica, 54(5), 1099-28.

Demertzis, M., Hughes-Hallet, A. and Viegi, N. (2004), "An independent central bank faced with elected governments," European Journal of Political Economy 20, 907-22.

Demertzis, Maria, A. Hughes Hallet (2007), "Central Bank Transparency in Theory and Practice," Journal of Macroeconomics, Volume 29, Issue 4, 760-789.

Dincer, N. Nergiz and Barry Eichengreen (2007), "Central Bank Transparency: Where, Why, and with What Effects?" NBER Working Paper 13003. 
Eijffinger, S.C.W. and P.M. Geraats (2006), "How transparent are central banks?" European Journal of Political Economy 22, 1-21.

Eijffinger, S.C.W. and van der Cruijsen, C. (2010), "The Economic Impact of Central Bank Transparency: A Survey," in: P. Siklos, M. Bohl and M. Wohar(eds.), Challenges in central banking: The present institutional environment and the forces affecting the conduct of monetary policy, Cambridge University Press (forthcoming).

Faust, J. and L. E. O. Svensson (2001), "Transparency and Credibility: Monetary Policy with Unobservable Goals," International Economic Review 42, 369-07.

Futagami, K., Y. Morita and A. Shibata (1993), "Dynamic Analysis of and Endogenous Growth Model with Public Capital," Scandinavian Journal of Economics, Vol. 95, pp. 607-25.

Geraats, Petra M. (2002), "Central Bank Transparency,” The Economic Journal, 112, 532-65.

Geraats, Petra M. (2007) "Political pressures and monetary mystique", CESIFO Working Paper No. 1999.

Ghosh, S. and U. Roy (2004), "Fiscal Policy, Long-Run Growth, and Welfare in a Stock-Flow Model of Public Goods," Canadian Journal of Economics, Vol. 37, pp. 742-756.

Glomm, G. and B. Ravikumar (1997), "Productive government expenditures and long-run growth," Journal of Economic Dynamics and Control 1 (1), pp. 183-204.

Grüner, Hans Peter (2002), "How Much Should Central Banks Talk? A New Argument," Economics Letters 77, 195-8.

Hassler, J., K. Storesletten and F. Zilibotti (2007), "Democratic public good provision," Journal of Economic Theory 133 (1), 127-51.

Hefeker, Carsten and Blandine Zimmer, (2010), "Uncertainty and fiscal policy in an asymmetric monetary union," Open Economies Review, forthcoming.

Hughes Hallett, A., and D. N. Weymark (2005): "Independence before Conservatism: Transparency, Politics and Central Bank Design", German Economic Review, 6, 1-21.

Hughes Hallett, Andrew and Jan Libich (2006), "Central Bank Independence, Accountability and Transparency: Complements or Strategic Substitutes?", CEPR Discussion Paper No. 5470.

Hughes Hallett, Andrew and Jan Libich (2009), "Explicit Inflation Targets, Communication, and Central Bank Independence: Friends or Foes?" Mimeo.

Hughes-Hallett, A. and Viegi, N. (2003), "Imperfect transparency and the strategic use of information in monetary policy: An ever present temptation for central bankers", The Manchester School, 71, 498-520.

Ismihan, Mustafa and F. Gulcin Ozkan (2004), "Does central bank independence lower inflation?" Economics Letters 84, 305-09.

Ismihan, Mustafa and F. Gulcin Ozkan (2007), "Public investment: a remedy or a curse? Examining the Role of Public Investment for Macroeconomic Performance," CEPR Discussion Papers 6139.

Jensen, H. (2002), “Optimal degrees of transparency in monetary policy making," Scandinavian Journal of Economics 104, 399-422.

Klein, P., P. Krusell and J.V. Rios-Rull (2008), “Time-consistent public expenditures," Review of Economic Studies 75 (3), pp. 789-808.

Mittnik, S., Neumann, T. (2001), "Dynamic effects of public investment: vector autoregressive evidence from six industrialized countries," Empirical Economics 26, 429-46.

Morris, Steven and Hyun Shin (2002), "The Social Value of Public Information", American Economic Review 92, 1521-34.

Morrison, C. and A. E.Schwartz (1996), "State infrastructure and productive performance," American Economic Review 86, 1095-111. 
Nolan, C. and E. Schaling (1998), "Monetary Policy Uncertainty and Inflation: The Role of Central Bank Accountability," De Economist 146, 585-602.

Pereira, A. (2000), "Is all public capital created equal?" Review of Economics and Statistics 82, 513-18.

Sorensen, J.R. (1991), "Political uncertainty and macroeconomic performance," Economics Letters, 37, 377-81.

Walsh, Carl E. (2003), “Accountability, Transparency, and Inflation Targeting”, Journal of Money, Credit, and Banking, 35(5), 829-49. 


\title{
Documents de travail du BETA
}

\author{
2010-01 The Aggregation of Individual Distributive Preferences through the Distributive Liberal Social \\ Contract : Normative Analysis \\ Jean MERCIER-YTHIER, janvier 2010. \\ 2010-02 Monnaie et Crise Bancaire dans une Petite Economie Ouverte \\ Jin CHENG, janvier 2010. \\ 2010-03 A Structural nonparametric reappraisal of the $\mathrm{CO}_{2}$ emissions-income relationships \\ Theophile AZOMAHOU, Micheline GOEDHUYS, Phu NGUYEN-VAN, janvier 2010. \\ 2010-04 The signaling role of policy action \\ Romain BAERISWYL, Camille CORNAND, février 2010. \\ 2010-05 Pro-development growth and international income mobility: evidence world-wide \\ Jalal EL OUARDIGHI, mars 2010. \\ 2010-06 The determinants of scientific research agenda: Why do academic inventors choose to \\ perform patentable versus non-patentable research? \\ Caroline HUSSLER, Julien PENIN, mars 2010. \\ 2010-07 Adverse Selection, Emission Permits and Optimal Price Differentiation \\ Mourad AFIF, Sandrine SPAETER, mars 2010. \\ 2010-08 The impact of ambiguity on health prevention and insurance \\ Johanna ETNER, Sandrine SPAETER, mars 2010.
}

2010-09 Equité du plaider coupable : une analyse économétrique dans trois tribunaux de grande instance français.

Lydie ANCELOT, mars 2010.

2010-10 Networks, Irreversibility and Knowledge Creation.

Patrick LLERENA, Muge OZMAN, mars 2010.

2010-11 Les clusters et les réseaux comme fondements de la dynamique d'innovation dans l'industrie biopharmaceutique

Marc Hubert DEPRET, Abelillah HAMDOUCH, avril 2010.

2010-12 Large-scale risks and technological change: What about limited liability? Julien JACOB, Sandrine SPAETER, avril 2010.

2010-13 Innovation and Development. The Evidence from Innovation Surveys

Francesco BOGLIACINO, Giulio PERANI, Mario PIANTA, Stefano SUPINO, avril 2010.

2010-14 Cooperative provision of indivisible public goods

Pierre DEHEZ, juin 2010.

2010-15 Implications de l'imperfection des marchés financiers pour la politique monétaire Meixing DAl, juin 2010. 
2010-16 Bank lending networks, experience, reputation and borrowing costs.

Christophe J. GODLEWSKI, Bulat SANDITOV, Thierry BURGER-HELMCHEN, juin 2010.

2010-17 Les déterminants individuels des absences au travail : une comparaison européenne.

Sabine CHAUPAIN-GUILLOT, Olivier GUILLOT, juin 2010.

2010-18 Fiscal policy efficiency and coordination: The New Open Economy Macroeconomics Approach.

Gilbert KOENIG, Irem ZEYNELOGLU, juillet 2010.

2010-19 Financial market imperfections and monetary policy strategy. Meixing DAl, juillet 2010.

2010-20 Analyse multidimensionnelle de l'insertion professionnelle des étudiants de bac+5: approche par les parcours de formation et le capital social.

Philippe CORDAZZO, Magali JAOUL-GRAMMARE, juillet 2010.

2010-21 Monetary and fiscal policy interactions with central bank transparency and public investment Meixing DAI, Moïse SIDIROPOULOS, septembre 2010.

La présente liste ne comprend que les Documents de Travail publiés à partir du $1^{\mathrm{er}}$ janvier 2010 . La liste complète peut être donnée sur demande.

This list contains the Working Paper writen after January 2010, 1rst. The complet list is available upon request. 